\title{
Assessing the potential determinates of national vitamin A supplementation in Ethiopia.
}

Tadele Abate Lucha ( $\square$ lucha.tadele@yahoo.com )

Kotebe Metropolitan University

Admassu Ketsela

Kotebe Metropolitan University

\section{Teklu Assefa Engida}

Kotebe Metropolitan University

\section{Research Article}

Keywords: Vitamin A supplementation, children, Ethiopia

Posted Date: February 21 st, 2022

DOI: https://doi.org/10.21203/rs.3.rs-1352875/v1

License: (c) (1) This work is licensed under a Creative Commons Attribution 4.0 International License. Read Full License 


\section{Abstract}

Background: Vitamin A is a nutrient that is required in a small amount for normal visual system function, growth and development, epithelia's cellular integrity, immune function, and reproduction. Vitamin A has a significant and clinically important effect since it has been associated with a reduction in all-cause and diarrhea mortality. The aim of this study was to determine factors associated with national vitamin $A$ supplementation among children aged 6-35 months by using data from the 2019 Ethiopia Mini Demographic and Health Survey.

Method: The study used a population-based cross-sectional study design to assess factors associated with vitamin A supply among children aged 6 to 35 months in the six months before the survey's start. Descriptive statistics were used to identify the proportion of children who had taken vitamin A supplements, after which multivariable logistic regression analysis was carried out to determine the predictors of vitamin A supplementation.

Result: The overall coverage of vitamin A supplementation among children aged 6-35 months for the survey included was $46 \%$. In the multivariable analysis, children who resided in urban areas [AOR $=1.34$ $(95 \% \mathrm{Cl}: 1.00,1.81)]$ were more likely to receive vitamin A supplementation than children living in rural areas. Postnatal care recipients were 1.5 times more likely than non-recipients to obtain vitamin $A$ capsules for their children [AOR $=1.54(95 \% \mathrm{Cl}: 1.20,1.97)]$. Mothers [AOR $=1.26,95 \% \mathrm{Cl}: 1.029,1.57$ ] who delivered at health facilities were $26 \%$ more likely to receive vitamin A capsules for their children than those who delivered at home. Other factors that were associated with higher a likelihood of vitamin $A$ supplementation were: number of antenatal visits, age of child, and household wealth index.

Conclusion: The coverage of vitamin A supplementation set by the Ethiopia ministry of health remains low and it is strongly associated with antenatal visit, postnatal checkups and place of delivery. Expanding institutional delivery and maternal health services like ANC and PNC should be prioritized.

\section{Background}

Vitamin $\mathrm{A}$ is a nutrient that is required in a small amount for normal visual system function, growth and development, epithelia's cellular integrity, immune function, and reproduction [1]. Vitamin A has a significant and clinically important effect since it has been associated with a $12 \%$ and $34 \%$ reduction in all-cause and diarrhea mortality [2, 3]. In Ethiopia, between 169,563 and 376,030 child lives have been saved as a result of vitamin A supplementation over the last fifteen years [4]. Additionally, vitamin A deficiency was found to be linked to childhood stunting $[5,6]$

Globally, the prevalence of VAD-related vision loss increased from $68.8 \%$ per 100,000 people in 1990 to 75.1 percent in 2017 [7]. In 2016, 64\% of children in need in priority countries received two doses of vitamin $A$, but more than 140 million children were left behind, putting them at risk of disease and death [8]. 
So far, $14.5 \%$ of Ethiopian preschool children have VAD, and vitamin A deficiency remains a moderate public health problem in the country [9].

In low-income countries, vitamin A supplementation for children aged 6-59 months is being introduced in child health programs. In many countries, however, vitamin A supplementation coverage is less than $80 \%$ and 5.2 million preschool-age children have clinical vitamin A deficiency [10]. In sub-Saharan African countries, the overall coverage of vitamin A supplementation among children aged 6-59 months was $59.4 \%[11]$.

In Ethiopia, based on the global nutrition report, the coverage of two high-dose vitamin A supplements was $66 \%$ by 2020 [12], and at least $75 \%$ of the targeted population received at least one dose of vitamin $A$ throughout the last 14 years (2005-2018) [4].

According to the Ethiopian demographic and health survey (EDHS), $46.8 \%, 53 \%$, and $45 \%$ of eligible children received the supplement in the last six months of the survey in 2005, 2011, and 2016, respectively [13-15], but this percentage is still low when compared to the Ethiopian ministry of health's goal of increasing the proportion of children aged 6-59 months who receive vitamin A supplementation to $95 \%$ by the end of 2020 [16].

Therefore, this study aimed to use the 2019 EMDHS to determine factors that predict VAS in children aged 6-35 months. This may help to evaluate the Ethiopian ministry of Health's health sector transformation plan (HSTP), which targets increasing the proportion of children aged 6-59 months who receive vitamin A supplementation to $95 \%$ by the end of 2020 [16].

\section{Methods And Materials}

\section{Data source}

The data for this study was extracted from the 2019 EMDHS [15]. The 2019 EMDHS is the second EMDHS and the fifth DHS implemented in Ethiopia. The survey was conducted in nine regional states and two city administrations of Federal Democratic Republic of Ethiopia [17].

\section{Sampling and data collection}

The 2019 EMDHS sample was stratified and selected in two stages. Each region was stratified into urban and rural areas, yielding 21 sampling strata. In the first stage, a total of 305 enumeration areas (93 in urban areas and 212 in rural areas) were selected with probability proportional to enumeration area size based on the 2019 Ethiopian Population and Housing Census (EPHC) frame and with independent selection in each sampling stratum [17]. In the second stage of selection, a fixed number of 30 households per cluster were selected with an equal probability systematic selection from the newly created household listing. All women aged 15-49, who were either permanent residents of the selected households or visitors who slept in the household the night before the survey were eligible to be interviewed [17]. women age 15-49 were interviewed using the Woman's questionnaire. 
The survey was conducted based on a nationally representative sample that provide estimate at the national and regional levels as well as for urban and rural areas. The survey interviewed 8,663 women of reproductive age (age 15-49) from a national representative sample of 8,663 households. Five questionnaires were used for the 2019 EMDHS: (1) the Household Questionnaire, (2) the Woman's Questionnaire, (3) the Anthropometry Questionnaire, (4) the Health Facility Questionnaire, and (5) the Fieldworker's Questionnaire. Only children aged 6-35 months who lived with an eligible respondent were included in our analysis, depending on the denominator of vitamin A supplements received in the six months before to the survey, resulting in a total weighted sample of 2290 women with children aged 635 months.

\section{Dependent variable}

The dependent variable for this study was vitamin A supplementation in the past 6 month among children aged 6-35 months. The response was recorded by asking the question, whether vitamin A dose was given in the last six months? The responses were recorded as either yes $=1$ or no $=0$.

\section{Independent variable}

The mother's education, maternal age, child age, household wealth index, religion, place of residence, region of residency, professional antenatal and postnatal care, place of delivery, mode of delivery, type of birth, sex of child, mother's marital status, and parity were the primary independent variables. They were selected from the available similar studies on the subject [18-20].

\section{Statistical analysis}

We use statistical package for social science (SPSS) version 25 was used for all analyses. To summarize the distribution of selected background characteristics of mothers and children, descriptive characteristics of the subjects were displayed as frequencies and percentages. The full model was performed with those variables showing $\mathrm{P}<0.25$ in the unadjusted analysis to evaluate the socioeconomic and demographic characteristics associated with vitamin A supplementation in the past 6 month (odds ratios with their $95 \%$ confidence intervals). Meanwhile, backward stepwise logistic regression was used to reduce the final model, and all variables in the final model had a $P<0.05$ [21]. With $95 \%$ confidence intervals, both unadjusted and adjusted odds ratios (OR) were presented $(95 \% \mathrm{Cl})$.

\section{Results}

\section{Characteristics of the respondents}

As summarized in Table 1, the majority of the children (74.5\%) lived in rural area, most of in the Oromia $(12.3 \%)$ and SNNPR (11.6\%). Half $(50.9 \%)$ of the mothers had no education. Overall, $54.2 \%$ of mothers were between the ages of 25 and 34 . At the time of the survey, the majority (93.6\%) said they were 
currently married. In terms of delivery place, $56.6 \%$ of mother gave birth in a hospital. Of these, $6.9 \%$ were delivered by cesarean section. Regarding antenatal visits, $32.2 \%$ of mothers reported having attended at least 1-3 antenatal visits during their pregnancy, while $41.8 \%$ reported having gone to more than 4 . Only $14.2 \%$ of babies had a post-natal checkup (Table 1 ). 
Table 1

Background characteristics of women with children aged 6-35 months of age in Ethiopia, EMDHS $2019(n=2290)$

\begin{tabular}{|c|c|c|}
\hline Background characteristics & Frequency (n) & Percent (\%) \\
\hline \multicolumn{3}{|l|}{ Region } \\
\hline Tigray & 184 & 8.0 \\
\hline Afar & 237 & 10.3 \\
\hline Amhara & 238 & 10.4 \\
\hline Oromia & 282 & 12.3 \\
\hline Somali & 194 & 8.5 \\
\hline Benishangul & 213 & 9.3 \\
\hline SNNPR & 266 & 11.6 \\
\hline Gambela & 186 & 8.1 \\
\hline Harari & 176 & 7.7 \\
\hline Addis Ababa & 145 & 6.3 \\
\hline Dire Dawa & 169 & 7.4 \\
\hline \multicolumn{3}{|l|}{ Place of residence } \\
\hline Urban & 584 & 25.5 \\
\hline Rural & 1706 & 74.5 \\
\hline \multicolumn{3}{|l|}{ Maternal Educational Level } \\
\hline No education & 1165 & 50.9 \\
\hline Primary & 782 & 34.1 \\
\hline Secondary/higher & 343 & 15.0 \\
\hline \multicolumn{3}{|l|}{ Religion } \\
\hline Orthodox & 729 & 31.8 \\
\hline Protestant & 447 & 19.5 \\
\hline Muslim & 1082 & 47.2 \\
\hline Traditional & 32 & 1.4 \\
\hline \multicolumn{3}{|l|}{ Age of Mother } \\
\hline $15-24$ & 628 & 27.4 \\
\hline
\end{tabular}




\begin{tabular}{|c|c|c|}
\hline Background characteristics & Frequency (n) & Percent (\%) \\
\hline $25-34$ & 1241 & 54.2 \\
\hline $35-49$ & 421 & 18.4 \\
\hline \multicolumn{3}{|l|}{ Wealth index } \\
\hline Poorest & 692 & 30.2 \\
\hline Poorer & 394 & 17.2 \\
\hline Middle & 340 & 14.8 \\
\hline Richer & 291 & 12.7 \\
\hline Richest & 573 & 25.0 \\
\hline \multicolumn{3}{|l|}{ Age of child (month) } \\
\hline $06-12$ & 609 & 26.6 \\
\hline $13-24$ & 987 & 43.1 \\
\hline $25-35$ & 694 & 30.3 \\
\hline \multicolumn{3}{|l|}{ Child sex } \\
\hline Male & 1189 & 51.9 \\
\hline Female & 1101 & 48.1 \\
\hline \multicolumn{3}{|l|}{ Currently marital status of mother } \\
\hline Married & 2144 & 93.6 \\
\hline No longer living together/separated & 146 & 6.4 \\
\hline \multicolumn{3}{|l|}{ Types of birth } \\
\hline Single birth & 2265 & 98.9 \\
\hline Twine & 25 & 1.1 \\
\hline \multicolumn{3}{|l|}{ Place of delivery } \\
\hline Home & 1040 & 45.4 \\
\hline Health & 1250 & 54.6 \\
\hline \multicolumn{3}{|l|}{ Mode of delivery } \\
\hline Normal (vaginal) & 2133 & 93.1 \\
\hline Cesarean section & 157 & 6.9 \\
\hline Antenatal care & & \\
\hline
\end{tabular}




\begin{tabular}{|lll|}
\hline Background characteristics & Frequency (n) & Percent (\%) \\
\hline No ANC visit & 594 & 25.9 \\
\hline $1-3$ & 738 & 32.2 \\
\hline $4+$ & 958 & 41.8 \\
\hline Post-natal check up & & \\
\hline No & 1965 & 85.8 \\
\hline Yes & 325 & 14.2 \\
\hline Parity & & \\
\hline $1-2$ & 939 & 41.0 \\
\hline $3-4$ & 626 & 27.3 \\
\hline $5-6$ & 428 & 18.7 \\
\hline $7+$ & 297 & 13.0 \\
\hline
\end{tabular}

\section{Level of vitamin A supplementation}

In this study, the prevalence of vitamin A supplementation within the last six months in Ethiopia was observed to be $46 \% 95 \% \mathrm{Cl}(44,48)$ (Table 2). There was regional variation in child vitamin $\mathrm{A}$ supplementation, with Tigray $60 \%$, Gambela $59 \%$, Amhara 58\%, Benishangul $57 \%$, SNNPR $34 \%$, Afar $30 \%$ and Somalia 19\% (Table 2). 
Table 2

Vitamin A supplementation among children aged 635 months in the regional administration of Ethiopia, EMDHS $2019(n=2290)$

\begin{tabular}{|lll|}
\hline Region & Numbers & Percentage, 95\% Cl \\
\hline Tigray & 184 & $60 \%,(53 \%, 67 \%)$ \\
\hline Afar & 237 & $30 \%,(24 \%, 36 \%)$ \\
\hline Amhara & 238 & $58 \%,(52 \%, 65 \%)$ \\
\hline Oromia & 282 & $42 \%,(36 \%, 48 \%)$ \\
\hline Somali & 194 & $19 \%,(13 \%, 25 \%)$ \\
\hline Benishangul & 213 & $57 \%,(51 \%, 64 \%)$ \\
\hline SNNPR & 266 & $34 \%,(28 \%, 40 \%)$ \\
\hline Gambela & 186 & $59 \%,(51 \%, 66 \%)$ \\
\hline Harari & 176 & $49 \%,(41 \%, 56 \%)$ \\
\hline Addis Ababa & 145 & $44 \%,(36 \%, 52 \%)$ \\
\hline Dire Dawa & 169 & $56 \%,(49 \%, 64 \%)$ \\
\hline Total (Ethiopia) & 1043 & $46 \%,(44 \%, 48 \%)$ \\
\hline
\end{tabular}

\section{Vitamin A supplementation by place of residence}

Among children aged 6-35 months, those in urban (54\%) and rural (43\%) areas received a vitamin A supplement in the 6 months before the survey (Table 3).

Table 3

Vitamin A supplementation among children aged 6-35 months in Ethiopia, by place of residence, EMDHS 2019 $(n=2290)$.

\begin{tabular}{|lll|}
\hline Place of residence & Numbers & Percentage, 95\% Cl \\
\hline Urban & 584 & $54 \%,(50 \%, 58 \%)$ \\
\hline Rural & 1706 & $43 \%,(40 \%, 45 \%)$ \\
\hline
\end{tabular}

\section{Factors associated with vitamin A supplementation}

The result of multivariable analysis reveals that antenatal care, place of delivery, age of child, postnatal checkup, place of residence, and household wealth index were independently and significantly associated 
with vitamin A supplementation.

Mothers who had $1-3$ ANC visits $[A O R=2.21(95 \% \mathrm{Cl}: 1.65,2.73)]$ and those who had four or more ANC visits $[A O R=2.49(95 \% \mathrm{Cl}: 1.93,3.24)]$ were 2.2 and 2.4 times more likely to receive vitamin A capsules for their children, respectively, than mothers who had no ANC visits. Place of delivery: When compared to mothers who gave birth at home, mothers who gave birth at a health facility were $26 \%$ more likely to receive vitamin A capsules for their children [AOR $=1.26$ [95\% Cl: 1.02, 1.57]]. (Table 4). 
Table 4

Multivariate logistic regression analysis of factors associated with children's receipt of a vitamin A capsule in the last six months in Ethiopia, EMDHS 2019

\begin{tabular}{|c|c|c|c|c|}
\hline \multirow[t]{2}{*}{ Characteristics } & \multicolumn{2}{|c|}{$\begin{array}{l}\text { Vitamin A supplements in the past } 6 \\
\text { month }\end{array}$} & \multirow[t]{2}{*}{ COR at $95 \% \mathrm{Cl}$} & \multirow[t]{2}{*}{ AOR at $95 \% \mathrm{Cl}$} \\
\hline & No & Yes & & \\
\hline \multicolumn{5}{|l|}{ Place of residence } \\
\hline Urban & 271 & 313 & $\begin{array}{l}1.54(1.27 \\
1.86)\end{array}$ & ${ }_{*}^{1.34}(1.00,1.81)$ \\
\hline Rural & 976 & 730 & 1 & 1 \\
\hline \multicolumn{5}{|c|}{$\begin{array}{l}\text { Maternal Educational } \\
\text { Level }\end{array}$} \\
\hline No education & 691 & 474 & 1 & 1 \\
\hline Primary & 405 & 377 & $\begin{array}{l}1.35(1.13, \\
1.62)\end{array}$ & $1.12(0.91,1.39)$ \\
\hline Secondary/higher & 151 & 192 & $\begin{array}{l}1.85(1.45 \\
2.36)\end{array}$ & $1.24(0.92,1.67)$ \\
\hline \multicolumn{5}{|l|}{ Age of Mother } \\
\hline $15-24$ & 364 & 264 & 1 & 1 \\
\hline $25-34$ & 668 & 573 & $\begin{array}{l}1.18(0.97 \\
1.43)\end{array}$ & $1.14(0.93,1.40)$ \\
\hline $35-49$ & 215 & 206 & $\begin{array}{l}1.32(1.03 \\
1.69)\end{array}$ & $1.31(1.00,1.70)$ \\
\hline \multicolumn{5}{|l|}{ Wealth index } \\
\hline Poorest & 458 & 234 & 1 & 1 \\
\hline Poorer & 220 & 174 & $\begin{array}{l}1.54(1.20 \\
1.99)\end{array}$ & $1.19(0.91,1.56)$ \\
\hline Middle & 157 & 183 & $\begin{array}{l}2.28(1.75 \\
2.97)\end{array}$ & ${ }_{\star \star}^{1.74}(1.31,2.31)$ \\
\hline Richer & 140 & 151 & $\begin{array}{l}2.11(1.59, \\
2.79)\end{array}$ & ${ }_{*}^{1.35}(1.00,1.84)$ \\
\hline Richest & 272 & 301 & $\begin{array}{l}2.16(1.72, \\
2.71)\end{array}$ & $0.92(0.69,1.39)$ \\
\hline \multicolumn{5}{|c|}{ Age of child (month) } \\
\hline $06-12$ & 396 & 213 & 1 & 1 \\
\hline
\end{tabular}




\begin{tabular}{|c|c|c|c|c|}
\hline \multirow[t]{2}{*}{ Characteristics } & \multicolumn{2}{|c|}{$\begin{array}{l}\text { Vitamin A supplements in the past } 6 \\
\text { month }\end{array}$} & \multirow[t]{2}{*}{ COR at $95 \% \mathrm{Cl}$} & \multirow[t]{2}{*}{ AOR at $95 \% \mathrm{Cl}$} \\
\hline & No & Yes & & \\
\hline $13-24$ & 502 & 485 & $\begin{array}{l}1.79(1.45 \\
2.21)\end{array}$ & $1.84(1.48,2.29)$ \\
\hline $25-35$ & 349 & 345 & $\begin{array}{l}1.83(1.47 \\
2.29)\end{array}$ & $1.86(1.47,2.34)$ \\
\hline \multicolumn{5}{|l|}{ Place of delivery } \\
\hline Home & 667 & 373 & 1 & 1 \\
\hline Health facility & 580 & 670 & $\begin{array}{l}2.06(1.74 \\
2.44)\end{array}$ & ${ }_{*}^{1.26}(1.02,1.57)$ \\
\hline \multicolumn{5}{|l|}{ Antenatal care } \\
\hline No ANC visit & 436 & 158 & 1 & 1 \\
\hline $1-3$ & 379 & 359 & $\begin{array}{l}2.61(2.07 \\
3.29)\end{array}$ & $2.21(1.65,2.73)$ \\
\hline $4+$ & 432 & 526 & $\begin{array}{l}3.36(2.69, \\
4.19)\end{array}$ & $2.49(1.93,3.24)$ \\
\hline \multicolumn{5}{|c|}{ Post-natal check up } \\
\hline No & 1118 & 847 & 1 & 1 \\
\hline Yes & 129 & 196 & $\begin{array}{l}2.00(1.57 \\
2.54)\end{array}$ & $\underset{*}{1.54}(1.20,1.97)$ \\
\hline
\end{tabular}

Age of child, older children were significantly more likely to receive VAS than those aged 6-12 months. Place of residence, children who resided in urban areas were significantly more likely to receive VAS compared with children living in rural areas (Table 4)

In terms of the postnatal checkup, postnatal care recipients were 1.5 times more likely than non-recipients to obtain vitamin A capsules for their children [AOR $=1.54(95 \% \mathrm{Cl}: 1.20,1.97)$ ]. Finally, children from the richer and middle-wealth quintiles had higher odds of receiving a vitamin A capsule in comparison to children from the poorest wealth quintile (Table 4).

\section{Discussion}

Based on data from the Ethiopian Demographic and Health Survey, this population-based study was used to assess the factors associated with vitamin A supplementation in children aged 6-35 months.

Correspondingly, the number of antenatal visits, place of delivery, age of child, postnatal checkup, place of residence, and household wealth index were independently and significantly associated with vitamin A supplementation. 
In this study, children who resided in urban areas were 1.3 times more likely to receive VAS than children living in rural areas. This finding is supported by similar studies conducted in India and sub-Saharan African countries $[11,18]$. The possible reasons for the difference between the two areas might be attributed to differences in accessibility to health information and health services, infrastructure, and technological advancements, and also time to reach the health facility [22, 23]. Place of delivery also significantly associated with VAS. When compared to mothers who gave birth at home, mothers who gave birth at a health facility were $26 \%$ more likely to receive vitamin A capsules for their children. This finding supported by previous study in Ethiopia [24] and Nigeria [25].

This might be because mothers who delivered at a health facility may be supported and get information about the importance of vitamin A supplementation, and health professionals tend to facilitate vitamin $A$ supplementation compared to those who gave birth at home [26, 27].

The other most important variable significantly associated with VAS was the number of antenatal visits. Mothers who had 1-3 ANC visits and those who had four or more ANC visits were 2.2 and 2.4 times more likely to receive vitamin A capsules for their children, respectively, than mothers who had no ANC visits. The finding was supported by a study in Nigeria [25] and national studies [24, 28, 29]. This could be attending antenatal care during pregnancy. The health professionals encourage, educate, and counsel the mother about the benefits of vitamin A and the consequences of VAD. It helps the mother to get information about VAS and immunizations, so it can increase the chance of receiving a vitamin A capsule for their children $[27,29]$. The result indicates children whose mothers had no ANC follow-up were more likely to suffer from VAD [30].

Our study also discovered that the household wealth index was significantly related to VAS. Children from the richer and middle-wealth quintiles had higher odds of receiving a vitamin A capsule in comparison to children from the poorest wealth quintile. This is supported by study conduct in Bangladeshi [20] and Nigeria [31]. The possible explanation might be better household wealth standing may improve uptake of the supplement through advancing access to health information and mitigating economic barters for seeking health care. One study shows children from the poorest family are more vitamin A deficient compared to those in richer family [32].

In this study, postnatal checkup and age of child also significantly associated with vitamin A supplementation.

We used data from the 2019 EMDHS, which is a national survey, which is one of the study's strengths. As a result, the findings of the study have significant consequences at the individual, community, and policy levels. The key drawback is that it is prone to recall bias. The study's other limitations were that it overlooked certain crucial potential factors that influence practice due to incomplete data.

\section{Conclusion}


In our study, both individual and community-level factors were significantly associated with vitamin A supplementation. Variables like the number of antenatal visits, place of delivery, age of child, postnatal checkup, place of residence, and household wealth index were independently and significantly associated with vitamin A supplementation.

Therefore, the authors recommend increasing special awareness, especially for mothers who deliver at home, with no antenatal follow-up and postnatal checkup, by expanding institutional delivery and maternal health services like ANC and PNC.

\section{Abbreviations}

AOR: Adjusted odds ratio; COR: Crude odds ratio; Cl: Confidence interval; DHS: Demographic and Health Survey; EMDHS: Ethiopia Mini Demographic and Health Survey; EPHC: Ethiopian Population and Housing Census; SNNP: Southern Nations Nationalities and Peoples; VAS: vitamin A supplementation; VAD: vitamin A deficiency;

\section{Declarations}

\section{Ethical approval and consent to participate}

All ethical considerations as prescribed by Helsinki Declaration were followed. This study is a secondary data analysis of the EMDHS, which is publicly available, approval was sought from MEASURE DHS/ICF International and permission was granted for this use. The original DHS data were collected in conformity with international and national ethical guidelines. Ethical clearance was provided by the Ethiopian Public Health Institute (EPHI) Review Board, the National Research Ethics Review Committee (NRERC) at the Ministry of Science and Technology, the Institutional Review Board of ICF International, and the United States Centers for Disease Control and Prevention (CDC). Written consent was obtained from mothers/caregivers and data were recorded anonymously at the time of data collection during

the EMDHS 2019.

\section{Consent for publication}

Not applicable

\section{Availability of data and material}

The survey datasets used in this study was based on publicly available dataset that is freely available online with no participant's identity from http://www.dhsprogram.com/data/available-datasets.cfm. The minimal data used for this study are available from the corresponding author on reasonable request.

\section{Competing interest}


The authors declare that they have no conflict of interest.

\section{Funding}

The authors received no specific funding for this work.

\section{Authors contribution}

TA, AK and TA designed the study, performed analysis and interpretation of data, and drafted the paper and revised the manuscript. All authors read and approved the final manuscript.

\section{Acknowledgment}

We would like to extend our heartfelt gratitude to the DHS project for providing us with the EMDHS 2019 dataset upon request.

\section{References}

1. Unit, N. and W.H. Organization, Global prevalence of vitamin A deficiency. 1995, World Health Organization.

2. Imdad, A., et al., Vitamin A supplementation for preventing morbidity and mortality in children from six months to five years of age. Cochrane database of systematic reviews, 2017(3).

3. Imdad, A., et al., Impact of vitamin A supplementation on infant and childhood mortality. BMC public health, 2011. 11(3): p. 1-15.

4. Laillou, A., et al., Vitamin A supplementation and estimated number of averted child deaths in Ethiopia: 15 years in practice (2005-2019). Maternal \& child nutrition, 2021. 17(3): p. e13132.

5. Ssentongo, P., et al., Association of vitamin A deficiency with early childhood stunting in Uganda: A population-based cross-sectional study. PLoS One, 2020. 15(5): p. e0233615.

6. Abdi, N.I., J. Mapesa, and J. Meme, Effect of Routine Vitamin a Supplementation on Nutritional Status of Children Aged 6-59 Months in Wajir County, Kenya. 2021.

7. Xu, Y., et al., Global patterns in vision loss burden due to vitamin A deficiency from 1990 to 2017. Public Health Nutrition, 2021. 24(17): p. 5786-5794.

8. UNICEF, Coverage at a crossroads: new directions for vitamin A supplementation programmes. New York, 2018.

9. Mekonen, T., et al., Prevalence and geographic distribution of vitamin A deficiency among preschool children in Ethiopia. Ethiopian Journal of public health and nutrition, 2020. 3(2).

10. Gilbert, C., R. Bowman, and A.N. Malik, The epidemiology of blindness in children: changing priorities. Community Eye Health, 2017. 30(100): p. 74.

11. Berde, A.S., P. Bester, and I.M. Kruger, Coverage and factors associated with vitamin A supplementation among children aged 6-59 months in twenty-three sub-Saharan African countries. 
Public health nutrition, 2019. 22(10): p. 1770-1776.

12. UNICEF. Child Health. 2021 [cited 202131 August ]; Available from:

https://data.unicef.org/resources/dataset/vitamin-supplementation.

13. Semba, R.D., et al., Coverage of the national vitamin A supplementation program in Ethiopia. Journal of tropical pediatrics, 2008. 54(2): p. 141-144.

14. USAID, S., et al., Ethiopia Demographic and Health Survey 2011, Central Statistical Agency Addis Ababa, Ethiopia ICF International Calverton, Maryland, USA; March 2012.

15. Ethiopia, F.D.R., Ethiopia Demographic and Health Survey 2016. Addis Ababa Ethiopia, and Rockville. 2016, CSA ICF Maryland, USA.

16. Ethiopia, F., Health Sector Transformation Plan (HSTP): 2015/16-- 2019/20, Addis Ababa. 2015, Ethiopia.

17. Ethiopian Public Health Institute - EPHI, Federal Ministry of Health - FMoH, and ICF, Ethiopia Mini Demographic and Health Survey 2019. 2021, EPHI/FMoH/ICF: Addis Ababa, Ethiopia.

18. Srivastava, S. and S. Kumar, Does socio-economic inequality exist in micro-nutrients supplementation among children aged 6-59 months in India? Evidence from National Family Health Survey 2005-06 and 2015-16. BMC Public Health, 2021. 21(1): p. 1-12.

19. Marjan, N., et al., Factors associated with coverage of vitamin a supplementation among Bangladeshi children: mixed modelling approach. BMC Public Health, 2021. 21(1): p. 1-11.

20. Abedin, M.M., et al., Assessing and Determining Potential Factors Associated with Vitamin A Supplementation in Bangladesh. Biostat Biometrics, 2019. 9(1): p. 10.19080.

21. Pallant, J., SPSS survival manual: A step by step guide to data analysis using IBM SPSS. 2020: Routledge.

22. Oiye, S., et al., Programmatic implications of some vitamin A supplementation and deworming determinants among children aged 6-59 months in resource-poor rural Kenya. Pan African Medical Journal, 2019. 32(1).

23. Muchabaiwa, L., et al., Determinants of maternal healthcare utilization in Zimbabwe. Int J Econ Sci Appl Res, 2012. 5(2): p. 145-162.

24. Gilano, G., S. Hailegebreal, and B.T. Seboka, Geographical variation and associated factors of vitamin A supplementation among 6-59-month children in Ethiopia. Plos one, 2021. 16(12): p. e0261959.

25. Dahiru, T., et al., Determinants of Vitamin A Uptake in Nigeria: The Role of Contextual Factors. Journal of Advances in Medicine and Medical Research, 2018. 25(7): p. 1-14.

26. Ruducha, J., et al., How Ethiopia achieved millennium development goal 4 through multisectoral interventions: a countdown to 2015 case study. The Lancet Global Health, 2017. 5(11): p. e1142e1151.

27. Mekonnen, Z.A., et al., Multilevel analysis of individual and community level factors associated with institutional delivery in Ethiopia. BMC Research Notes, 2015. 8(1): p. 376. 
28. Gebremedhin, T., et al., Micronutrient intake status and associated factors among children aged 623 months in the emerging regions of Ethiopia: A multilevel analysis of the 2016 Ethiopia demographic and health survey. PloS one, 2021. 16(10): p. e0258954.

29. Haile, D., S. Biadgilign, and M. Azage, Differentials in vitamin A supplementation among preschoolaged children in Ethiopia: evidence from the 2011 Ethiopian Demographic and Health Survey. Public Health, 2015. 129(6): p. 748-754.

30. Temesgen, $H_{\text {., }}$ et al., Dietary diversity feeding practice and its associated factors among children age 6-23 months in Ethiopia from 2011 up to 2018: a systematic review and meta-analysis. Italian journal of pediatrics, 2018. 44(1): p. 1-10.

31. Aghaji, A.E., R. Duke, and U.C. Aghaji, Inequitable coverage of vitamin A supplementation in Nigeria and implications for childhood blindness. BMC public health, 2019. 19(1): p. 1-8.

32. Kundu, S., B. Rai, and A. Shukla, Prevalence and determinants of Vitamin A deficiency among children in India: Findings from a national cross-sectional survey. Clinical Epidemiology and Global Health, 2021. 11: p. 100768. 